\title{
O PARTICULARISMO MORAL E A ÉTICA ARISTOTÉLICA*
}

\author{
Marco Zingano \\ Universidade de São Paulo
}

\begin{abstract}
Resumo: Este artigo pretende examinar questões centrais no particularismo moral de Jonathan Dancy a partir de uma comparação de suas principais teses com a ética aristotélica. Embora Dancy não reivindique uma linhagem aristotélica, será argumentado que tal comparação pode ser esclarecedora para o particularismo moral, bem com o para a ética aristotélica, especialmente no que concerne às regras que parecem não admitir qualquer exceção, como a proibição moral de agir com crueldade, ou o assassinato.
\end{abstract}

Keywords: Aristóteles, ética, particularismo moral, regras gerais.

Abstract: This paper purports to examine central issues in Jonathan Dancy's moral particularism by means of a comparison of its main tenets with Aristotelian ethics. Although Dancy does not vindicate an Aristotelian descent, it will be argued that such a comparison may be illuminating for moral particularism and Aristotelian ethics alike, notably in what concerns rules which do not seem to admit any exception whatsoever, as the moral ban on acting with cruelty, or on murder.

Keywords: Aristotle, ethics, moral particularism, general rules.

O particularismo moral é um rótulo conveniente para uma tese filosófica geral que foi paulatinanamente ganhando espaço nos debates recentes sobre questões éticas. Sob este rótulo geral incluem-se várias posições e pontos de vista, podendo mesmo haver conflito entre eles. Então, seria equivocado propor uma caracterização muito rígida de todos. Jonathan Dancy tem feito um considerável trabalho ao fornecer-nos uma ideia geral e uma clara diretriz conceitual sobre o que o particularismo moral parece ser, e agora seu nome está intimamente ligado a essa posição filosófica. Assim, parece justo perscrutar seus artigos para uma visão geral dos princípios mais importantes do particularismo moral. Deixem-me citar uma passagem que 
vem de um artigo editado por ele em 2001, mas que sofreu uma revisão substantiva em 2009:

"Particularism moral, at its most trenchant, is the claim that there are no defensible moral principles, that moral thought does not consist in the application of moral principles to cases, and that the morally perfect person should not be conceived as the person of principle. There are more cautious versions, however. The strongest defensible version, perhaps, holds that though there may be some moral principles, still the rationality of moral thought and judgment in no way depends on a suitable provision of such things; and the perfectly moral judge would need far more than a grasp on an appropriate range of principles and the ability to apply them. Moral principles are at best crutches that a morally sensitive person would not require, and indeed the use of such crutches might even lead us into moral error."1

Um leitor aristotélico certamente reconhecerá alguns traços familiares, especialmente a ideia da pessoa moral como alguém sensível às razões morais apresentadas caso a caso, que tomará decisões práticas hic et nunc, em conformidade com as circunstâncias, sem ser, necessariamente, guiado por regras morais previamente dadas. Entretanto, alguns outros tópicos soariam menos familiares, tal como a alegação de que não há princípios morais defensáveis, ou que princípios morais, quaisquer que sejam, são no melhor dos casos suportes que podem vir a ser moralmente desvantajosos. Esses pontos menos familiares não serão uma surpresa, pois Dancy nunca reivindicou que sua posição filosófica deveria ser vista como decorrente, ou proximamente conectada, à ética aristotélica. Contudo, um aroma distintivamente aristotélico pervade seus escritos. Mais precisamente, Dancy

\footnotetext{
* Este texto é a versão brasileira de Moral Particularism and Aristotelian Ethics, a ser publicado no livro editado por Gabriela Rossi, Nature and the Best Life - Exploring the Natural Bases of Practical Normativity in Ancient Philosophy (série Reason and Normativity / Vernunft und Normativität / Razón y Normatividad, ed. por A. M. González e A. G. Vigo), Georg Olms, Hildesheim-Zürich-New York, 2013. Agradeço a Gabriela Rossi pela permissão de publicar a versão portuguesa nesta revista. Igualmente, agradeço em especial a Alejandro Vigo pelos comentários e discussões a respeito deste tema.

1 DANCY, 2001, rev. 2009, p. 1. Obras particularmente importantes são também Dancy (1993) and (2004). B. Hooker and M. Little (2000) and J. Dreier (2006) apresentam excelentes discussões acerca do particularismo moral.
} 
parece capturar um ponto principal que vai diretamente ao cerne da ética como Aristóteles a concebe. Poderíamos afirmar cautelosamente esse ponto como a sua avaliação mais claramente positiva do papel central desempenhado por nós enquanto agentes, por assim dizer, particularmente sensíveis às razões morais, pela nossa tomada de decisão em conformidade com as circunstâncias precisas nas quais nos encontramos, sendo que nossa decisão permanece, de um modo importante, restrita ou limitada àquela exata situação a que a razão foi chamada a responder. Esse é certamente um ponto de vista bastante geral, mas isto empresta à posição de Dancy um matiz definitivamente aristotélico. Contraste isso, por exemplo, com a leitura de Barthélémy de Saint-Hilaire da ética de Aristóteles. Em uma nota de rodapé para a sua tradução francesa da Ética Nicomaquéia, ele francamente reclamou que 'a moralidade tem leis fixas e universais; Aristóteles parece esquecer-se disso muito seguidamente'. Isso é indubitavelmente não aristotélico; Dancy encontra-se no extremo oposto do espectro, e seguramente vai diretamente ao núcleo duro da ética aristotélica - até mesmo se objetássemos que não é claro quão longe ele vai ou quão longe deveria ir.

Assim, há um interesse filosófico em comparar as reflexões de Dancy com a filosofia moral de Aristóteles, embora o primeiro não prometa lealdade ao último. Entretanto, pode-se encontrar um tipo de dependência histórica, pois a conexão de Dancy com Aristóteles pode ser vista como indireta ou, mais propriamente, como curiosamente invertida. Sua filosofia desenvolveu-se, de um modo relevante, a partir de um diálogo e como uma resposta à ideia de deveres prima facie (ou razões contributórias, como Dancy prefere chamá-las) ${ }^{3}$. Como é bem conhecido, Ross é um mundialmente renomado estudioso da filosofia aristotélica e podemos esperar dele a elaboração de sua própria filosofia moral como fortemente influenciada por

\footnotetext{
2 SAINT-HILAIRE,1856, vol. I, p. 70.

${ }^{3} \mathrm{~A}$ expressão 'dever prima facie' pode ser equivocada, pois alguém pode entendê-la como significando somente um dever 'à primeira vista', o qual resultaria não ser realmente um dever, mas somente ter tido a aparência de um dever. Esse não é o significado de Ross, o qual seria melhor expresso pela ideia de uma característica que conta a favor ou contra uma ação, mas de tal modo que, em conjunção com outras características, ela pode ser aplicada onde, de uma forma geral, não deveria se comportar como prescreve. Usando uma frase latina, pode-se dizer que é alguma coisa como um dever pro tanto, um dever 'somente nessa medida; Dancy algumas vezes escreve 'pro tanto', mas prefere a expressão 'razão contributória', pois o último, por si mesmo, mostra mais claramente que isso pode ser contrabalançado por outras características. Ross também mantém que esse contrabalanço geral não é para ser equacionado com uma simples subordinação, pois não há princípios para determinar onde 0 equilíbrio reside. Ver W. D. Ross $(1930,2002)$ e (1939).
} 
alguns ou até mesmo pela maioria dos principais pontos que Aristóteles sustentou em seus tratados éticos. Mas na verdade é Dancy, pelo modo como ele reage à filosofia moral de Ross, quem, em um sentido mais profundo, parece renovar com as teses aristotélicas centrais sobre questões morais, pois, quando reage e recusa a abordagem de Ross sobre a moralidade, ele redescobre o que é hoje em dia reconhecido como uma tese aristotélica maior - a citação que fiz acima tenta capturá-la em uma breve apresentação -, denominada particularismo moral. De acordo, Dancy raramente e explicitamente retorna à, ou elabora questões exegéticas sobre a ética de Aristóteles. ${ }^{4}$ Mas essas conexões mais ou menos indiretas ou invertidas são de significância menor, pois o que é importante estudar em ambos os filósofos é como lidam com o problema moral sob o título geral de particularismo moral. Aqui, nós temos primeiramente que compreender quais são as suas principais concepções, e, então, proceder à avaliação de ambos com o intuito de decidir se, e em que extensão, Aristóteles defende uma ética particularista.

\section{$-I-$}

Deixem-me enfatizar, para começar, o que Dancy chama relevância variável. A ideia principal é que uma característica pode ter um valor moral em um caso, e um bem diferente em outro; em um primeiro caso, por exemplo, torna a ação muito melhor, mas, em um segundo caso, muito pior; e pode ainda não fazer diferença alguma em um terceiro caso. Como apresentado, pode-se temer um tipo de total indeterminação, com as mesmas características tendo efeitos muito diferentes em casos e situações diferentes. Essa anarquia ética pode ser boa para slogans e propaganda, mas dificilmente corresponde a nossa experiência moral. Por mais variável e, de certo modo, por mais radicalmente indeterminadas que as ações possam ser, elas ainda apresentam padrões irregulares, precisamente os padrões que governam as ações diárias e repetitivas às quais estamos habituados. De fato, embora possamos encontrar aqui e acolá traços dessa posição mais radical ou anárquica, a variabilidade, que é e permanece um aspecto central do particularismo moral ao longo das obras de Dancy, não é anárquica, e pode ser vista como não necessitando ser assim tão anárquica, pois a relevância

4 Um destes momentos ocorre em DANCY, 2004, p. 137-139, discutindo a teleologia aristotélica. 
variável está conectada diretamente à ideia de holismo em Dancy. E, como ele afirma, "o holismo, como o compreendo, é a alegação de que uma característica que tem um certo efeito sozinha, pode ter o efeito oposto em uma combinação". ${ }^{5}$ Isso abre espaço para alguma estabilidade no interior de uma instabilidade pervasiva.

Assim, uma característica tem um certo efeito por si mesma; e pode-se esperar que, a despeito de todas as variadas combinações na qual pode ser encontrada, e de todas as dificuldades que podem ser encontradas na tentativa de antecipar a consequência de uma determinada combinação, existem algumas regras que descreverão os valores morais e os resultados em qualquer combinação, ao menos aproximadamente, dado que, tomadas em si mesmas, todas as características tem um certo efeito. Assim, as generalizações seriam, uma vez mais, bem adequadas ao domínio moral, mesmo se acompanhadas por numerosas exceções e sub-regras governando essas exceções, estas mesmas abertas a novas exceções. ${ }^{6}$ Não podemos dizer, então, que o particularismo moral está procurando um caminho demasiado estrito e eventualmente intransponível quando vai de encontro à anarquia total, e ao mesmo tempo contra qualquer ética principialista?

De fato, Dancy está argumentando precisamente por tal caminho. Para fazer isso, ele introduz um novo conceito, que ele chama 'razão padrão' (default reason). Esse novo conceito não deveria ser assimilado à velha ideia de generalizações abertas a exceções, pois ele pretende explicar os padrões generalizantes na medida em que indica a inexequibilidade essencial de qualquer generalização. Em suas palavras, 'uma razão padrão é uma consideração que dá razões, a menos que algo a impeça de assim sê-lo'.7 A razão padrão introduz uma razão ceteris paribus. mentir é errado, outras coisas igualmente. Mas isso não deveria ser concebido como se o particularismo tivesse sido abandonado em nome de algum tipo de generalização em ética (com o único detalhe de que essas generalizações estão abertas a exceções), pois é importante ressaltar que uma razão padrão não é uma razão invariável, e não sendo uma razão invariável é tudo que se necessita para promover um quadro geralmente particularista. Não é somente

\footnotetext{
${ }^{5}$ DANCY, 2004, p. 8.

${ }^{6}$ Isso é algo que Kant tinha em mente em sua Paz Perpétua: veja a nota à segunda seção dos artigos definitivos, Akk. Edition p. 348. Como tal, isto não nos impede de propor um sistema moral baseado em regras e códigos gerais.

7 DANCY, 2004, p. 112.
} 
uma razão cujo valor mudou em uma determinada circunstância, mas antes, é uma razão mutável em qualquer circunstância. Em tal cenário, o que agora parece uma excrecência bizarra é precisamente a razão invariável, algo que vem agora como uma surpresa real. O cenário, desse modo, inverteu-se: a invariabilidade tem de ser explicada, não a variabilidade. Para citar Dancy novamente, "é como se tivéssemos uma visão do mundo amplamente holística, com traços de atomismo aqui e acolá”. ${ }^{8}$

Esse novo conceito pode ser visto como um compromisso, para, em vez de uma visão forte de que todas as características variam, nós temos agora a noção de que algumas seguramente variam, mas pode ser o caso de que algumas não. ${ }^{9}$ Mas tal compromisso seria equivocado. O ponto é que, de agora em diante, a relevância variável não somente leva a parte do leão, mas também, e de modo mais importante, captura a natureza de nossas proposições morais. Deixem-me lembrar parte da discussão que Dancy apresenta contra os deveres prima facie de Ross. De acordo com Dancy, a ideia chave no pensamento de Ross é que uma ação singular pode ter várias características, algumas das quais contam a seu favor e outras contra. Pesando todas as características umas contra as outras, há uma ação que é a única que devemos realizar especialmente. Podemos hesitar, ou estar em conflito, ou lamentar a sua escolha posteriormente - tudo isso é plausível em uma ética principialista, mas trata-se ainda e fundamentalmente de uma ética principialista, pois é importante notar que uma característica positiva ou negativa reterá sua valência alhures, mesmo que o balanço resultante seja diferente caso a caso. Disso podemos esperar produzir uma ética principialista, e Ross promete tal ética. Agora, "o particularista desafiará a assunção crucial de que o que é relevante em um caso é similar e necessariamente relevante em todos os casos". ${ }^{10}$ A relevância moral está assim profundamente enraizada nas circunstâncias, até mesmo se as características puderem ter, nelas mesmas, um valor positivo ou negativo. ${ }^{11}$ Mas a relevância moral é o que é crucial para decidir o que devemos fazer. A

8 DANCY, 2004, p. 118.

9 Ver PRICE, 2005, p. 191-212. Essa é uma discussão esclarecedora sob muitos aspectos; ver especialmente p. 204-206 para a valência variável.

10 DANCY, 2004, p. 7

${ }^{11}$ A noção de 'moral salience' (relevância moral) é um tópico importante no pensamento ético de John McDowell, cujas principais linhas estão de acordo com o particularismo moral; ver especialmente Mcdowell (1998; 2002). 
consequência é que uma ética principialista não é mais uma condição inevitável ou necessária.

Contudo, o que o particularista não desafiará é a impossibilidade dos princípios morais. $\mathrm{Na}$ verdade, o particularista aceita que algumas razões acabem por contribuir de maneira que não sejam afetadas por outras características. Um exemplo evidente deste valor invariável é a característica negativa de infligir dor gratuita a vítimas relutantes. Quaisquer que sejam as circunstâncias nas quais ocorre, isso reterá o seu valor negativo. Podemos pensar facilmente em outros exemplos: estupro, homicídio, e assim por diante. Não há razão para negar que eles retêm seu valor negativo em todas as circunstâncias, pois um particularista sustentará que sua invariância deriva não do fato de ser uma razão, mas do conteúdo peculiar daquela razão. Crueldade, por exemplo, vai contra a natureza humana, desde que geralmente, e como uma regra, esta evita a dor. Similarmente, o estupro tem de ser banido, como o homicídio, e não somente nessa ou naquela circunstância. Assim, o particularismo moral pode dar espaço para alguns princípios, contanto que não dependa de uma provisão de um conjunto de princípios morais como um sistema moral aceito. O particularismo moral não necessita, de fato, banir todas as regras; ele pode viver perfeitamente bem com elas, na medida em que não constituam uma condição necessária para ele. Podemos até mesmo imaginar uma moralidade que pudesse ser capturada em um conjunto holístico de princípios contributórios, constituindo o que seria corretamente descrito como uma ética principialista. Isso é possível, mas seria um acidente cósmico que um sistema da moralidade pudesse ser apreendido deste modo. Seria puro acaso, como Dancy afirma, sem explicação possível. Citando-o novamente:

"The thought that the existence of a suitable provision of principles would be a cosmic accident depends on the claim that there is no discernible need for such a provision. In a sense, this claim is a challenge to the opposition to come up with a picture of moral thought and judgement which, though it respects the truth of reasons-holism, still requires 
(rather than merely makes possible) a provision of principles that cover the ground." 12

\section{- II -}

Para a maioria dos comentadores, os preceitos morais em Aristóteles seguem uma estrutura geral básica, que é melhor descrita como generalizações 'nas mais das vezes', ou, para mencionar a expressão grega escolhida por Aristóteles, generalizações do tipo 'hôs epi to polu'. Tal estrutura refere-se a uma espécie de regularidade que carece de necessidade, e está, consequentemente, aberta a exceções. Ela pode ser expressa proveitosamente como 'a maioria dos F são G'. $A$ maioria dos $F$ são $G$ é compatível com poucos $F$ não são $G$. As exceções, os Fs que não são $G$ s, podem algumas vezes serem expressas por sub-regras, as quais, por sua vez, estão abertas à novas exceções. Podemos assim esperar um amplo e, por vezes, vasto complexo de regras e sub-regras. Supondo-se que todo o tipo de exceção pode ser expresso sob uma nova sub-regra, e que sua quantidade, mesmo considerável, é limitada ao fato de serem moralmente relevantes ${ }^{13}$, pode-se esperar eventualmente erradicar toda imprecisão, chegando a um (maior ou menor) complexo de regras e sub-regras que exaure todas as condições moralmente relevantes para um tipo de ação. Entretanto, isso seria uma falsa expectativa, não porque seja uma demanda excessiva em escala humana especificar todas as exceções (moralmente relevantes), mas especialmente porque, até mesmo se não houvesse demasiados níveis e se pudesse explicitar facilmente mais ou menos todas elas, a cada nível ainda encontraríamos uma indeterminação à espreita, pelo motivo de que não podem ser incorporadas em uma nova subregularidade. Metafisicamente falando, essas irregularidades estão enraizadas na matéria correspondente a cada nível, e não são mais do que o seu contrário, de maneira que qualquer estratégia, de modo que qualquer estratégia prescindindo delas falhará em eliminá-las conjuntamente das generalizações 'nas mais das vezes'. Dois tipos de exceções são assim

\footnotetext{
12 DANCY, 2004, p. 82

${ }^{13}$ As circunstâncias podem ser incontáveis, mas as que são moralmente relevantes parecem ser bem limitadas. Na realidade, Aristóteles apresenta uma pequena lista de circunstâncias moralmente relevantes na EN III 1: muito poucos tipos de item figuram nessa lista.
} 
distinguidas: (i) um primeiro conjunto é composto pelas que podem ser capturadas em novas sub- generalizações (e, dado que as exceções moralmente relevantes não são necessariamente incontáveis, pode-se presumir sub generalizá-las todas); (ii) um segundo conjunto é, entretanto, feito de exceções tais que não são mais assim do que não assim. Essas últimas exceções não seguem um padrão regular; elas são produtos da indeterminação radical que a matéria introduz no mundo sub-lunar. Por isso Aristóteles escreve que

\begin{abstract}
“algumas coisas acontecem por acaso, e da afirmação e da negação nenhuma é mais verdadeira do que a outra; com outras coisas, nas mais das vezes uma é mais suscetível de ocorrer do que a outra, mas ainda é possível para a outra ocorrer em vez desta." (De interp. 9 19ำ19-22) ${ }^{14}$
\end{abstract}

Isto é, há dois modos diferentes de não preencher os requisitos da necessidade: ou seguir uma regra 'nas mais das vezes', ou ser radicalmente indeterminado, e o último não apenas afasta a necessidade do mundo sublunar, mas também torna as generalizações irredutíveis a um conjunto exaustivo de regras e sub-regras.

Não é difícil encontrar passagens nas quais Aristóteles propõe tais generalizações "nas mais das vezes" em assuntos práticos. Eu citarei apenas dois exemplos: (i) no segundo do livro da Ética Nicomaquéia sobre a felicidade, no capítulo 2, Aristóteles discute se em todas as coisas devemos dar preferência ao pai e obedecê-lo, ou não; similarmente, ele menciona o problema de decidir se devemos prestar um serviço preferencialmente a um amigo ou a uma boa pessoa, e se devemos mostrar gratidão a um benfeitor ou favorecer um amigo, se não podemos fazer ambos. Após observar que tais questões são difíceis de determinar com precisão, Aristóteles afirma:

"Mas que não deveríamos dar a preferência em todas as coisas
para a mesma pessoa é bastante claro; e nós devemos nas mais das
vezes devolver o benefício antes que obsequiar os amigos, do
mesmo modo que devemos pagar um empréstimo a um credor
em vez de emprestar a um amigo." (ENIX 2 1164b30-34)

${ }^{14}$ Quase todas as traduções para o português vêm de J. Barnes (1984), com adaptações: as que não são têm referência à tradução utilizada. 
Ainda sobre a amizade, mas agora no décimo primeiro capítulo do primeiro livro sobre a amizade, Aristóteles escreve no mesmo espírito:

"A amizade entre irmãos é como a dos camaradas, pois eles são iguais e da mesma idade, e tais pessoas têm nas mais das vezes os mesmos sentimentos e caráter.” (ENVIII 11 1161a25-27)

Como eles têm os mesmos sentimentos e caráter nas mais das vezes, podemos razoavelmente esperar que eles se comportem da mesma maneira. Assim, segue que as regras ou preceitos morais concernentes a eles serão concebidas enquanto regras ou generalizações 'nas mais das vezes'. Agora, é tentador, e de fato muito provável, assumir que os preceitos morais são basicamente concebidos em Aristóteles como generalizações 'nas mais das vezes'. ${ }^{15}$ Eles produziriam, então, sentenças do tipo 'a maior parte dos $\mathrm{F}$ são G'. Isso é bastante plausível e tem algumas vantagens: (i) a universalização estrita é evitada, de modo que os preceitos morais podem ser mais facilmente compatíveis com exceções - ou as que possam ser, nelas mesmas, generalizadas em sub-regras ou as que resistem a quaisquer generalizações. Sentenças como 'sempre dizer a verdade' ou 'sempre manter suas promessas' soam demasiado estritas para serem consideradas seriamente como conselhos práticos bem formulados ou realmente criteriosos. Mas, 'dizer a verdade nas mais das vezes' parece bem promissor para uma ética humana; (ii) insuficientes no sentido de leis universais estritas, regras morais, contudo, nos dão diretrizes gerais que são muito proveitosas na vida diária, estendendo-se de regras práticas a quase-generalizações, como algumas mencionadas nas passagens do tratado da Ética Nicomaquéia sobre a amizade citadas acima. Assim, não há razão para não organizar as 'regras nas mais das vezes' em códigos e na legislação, pois servem como um bom gráfico moral para a agência humana; (iii) um terceiro ponto que não pode ser ignorado é que as

\footnotetext{
${ }^{15}$ Como Hardie afirma, "nós podemos esperar Aristóteles dizer também que, até mesmo se não podemos formular uma regra sem exceções, nós podemos reduzir o número de exceções se restringirmos as alegações da regra incorporando exceções em suas formulações (1980, p. 32-33). Entretanto, Hardie admite uma segunda razão para essas exceções, as quais derivam da 'sujeição dos fatos a uma certa variação imprevisivel' (a expressão vem de J. A. Smith), e inevitavelmente arruína o sonho de providenciar sub generalizações de modo exaustivo. Ver também Carlo Natali (2001): tendo reconhecido também a sujeição a uma variação imprevisivel, ele entretanto escreve que, "sem atingir a regularidade dos eventos físicos, campo da ação humana é suficientemente consistente para podermos formar um tipo de conhecimento concernente a isso que é, 'em geral', válido" (p. 34; edição italiana: p. 45).
} 
regras morais do tipo 'a maior parte dos F são G' são muito similares às leis nas ciências naturais, como Aristóteles as concebe. Comparem-nas 'a maior parte dos homens torna-se grisalha': aqui também há uma indeterminação inerradicável vivendo pacificamente nos limites de uma generalização flexível. Ações podem ser extremamente complexas e trazem consigo altos níveis de incerteza, ainda que não pareçam diferir radicalmente do que acontece na natureza, conforme a concepção aristotélica de ciência natural. A similaridade entre ambas as esferas, a prática e a teórica (no que se refere às ciências naturais), provavelmente conta como uma razão suplementar para sustentar que a fórmula básica do conselho moral segue o modelo 'nas mais das vezes' tão pervasivo nas ciências naturais, pois, desse modo, podemos encontrar uma forma e estrutura única para ambas, dado que elas não parecem diferir substancialmente uma da outra.

Entretanto, uma advertência parece ser requerida. Como Aristóteles as entende, as sentenças 'a maior parte dos F são G' não se limitam a revelar frequências de algum tipo. Poderia ser o caso que, porque $F$ é seguidamente ou muito seguidamente G, F é normalmente G, mas na realidade Aristóteles toma um outro caminho: porque $F$ é normalmente $G, F$ é seguidamente (frequentemente) G. ${ }^{16} \mathrm{~A}$ ideia é que sentenças 'a maior parte dos $\mathrm{F}$ são G' trazem consiga uma norma que se expressa ela própria em termos de frequência. 'A maioria dos homens torna-se grisalha' é não somente verdadeiro estatisticamente, ou não primariamente verdadeiro estaticamente, mas, também, e de modo mais importante, revela algo sobre a natureza dos homens, ser grisalho faz parte de sua natureza. E como isso revela (parte da) natureza do homem, é frequentemente verdadeiro que os homens tornam-se grisalhos. Contudo, a mesma dupla direção não parece ser aplicável na ética, ou pelo menos não diretamente. A maior das pessoas procura prazer, mas uma vida de prazer não é uma vida digna de ser vivida, ou ao menos na perspectiva moral de viver bem. Assim, em ética, a mesma relação dupla entre $G$ ser uma norma e a maior parte dos $F$ ser $G$ não parece ser o caso. Uma norma moral não procuraria prazer em toda a parte, ainda que a maioria dos homens busque o prazer onde estiver disponível. A analogia provavelmente contenha uma desanalogia: em assuntos práticos, a frequência não deve ser tomada como um sinal de normatividade. Mas, na realidade, essa desanalogia é somente parcial, pois se esperarmos encontrar uma razão para a frequência

${ }^{16}$ Ver especialmente T. Irwin (2000), que é a versão revisada de Irwin (1996). 
não ser um sinal de normatividade, nós indicamos que o mesmo modelo, aproximadamente, deve ser o caso para assuntos teóricos e práticos. E isso é precisamente o que Aristóteles faz. Na Ética Nicomaquéia, ele explica que, desde que o prazer aparece como um bem, mesmo que não o seja, nós escolhemos o prazeroso como um bem (e evitamos a dor como um mal), e, portanto, este se extravia. O prazer tem o poder de parecer bom, e todos nós nos empenhamos por ele; é por isso que somos seguidamente desencaminhados:

"Em tudo devemos precaver-nos principalmente contra o que é agradável e contra o prazer, pois não somos juízes imparciais quanto ao prazer. Havemos de sentir face ao prazer precisamente o que os anciãos sentiram diante de Helena e devemos proferir em todas estas situações a fala deles; afugentando assim o prazer, erraremos menos." (NE II 9 1109b7-12; trad. M. Zingano)

Podemos, dessa forma, manter a ideia de uma similaridade substancial entre normas práticas e leis naturais. Ambas trazem uma norma que explica (e, em alguns casos, requer) a frequência de seu acontecimento, exceto que, em assuntos práticos, a direção dupla entre norma e frequência é bloqueada por outros fatores (especialmente pelo poder desvirtuador do prazer). Nessa conjuntura, nós devemos recordar os deveres prima facie de Ross. Eles parecem apreender esse elemento de normatividade como se abrisse espaço para as regularidades. Um dever prima facie é aquele no qual a ação que ele comanda tem uma característica que nos dá uma razão moral para realizá-la, ou uma característica que é apropriada para algum aspecto das circunstâncias. Isso não é ainda um dever, nem muito menos um dever real ou próprio, pois essa característica pode, em uma determinada situação, ser sobrepujada ou excedida por outras, de modo que, embora sempre seja uma característica que é adequada para algum aspecto do mesmo, é superada por outras, e essas últimas expressam, naquela situação, o que é o correto a fazer. Mas elas mesmas se expressam como regras gerais, na medida em que sua normatividade está objetivamente fundamentada, a única que as características apropriadas revelam. Elas podem conflitar, e nós não temos nenhum algoritmo para decidir de antemão qual lado escolher. Todavia, elas são apresentadas corretamente sob a forma de regras gerais. Agora, isso também parece ser precisamente o que Aristóteles está fazendo, como vimos 
nas passagens sobre a amizade citadas acima, onde ele propõe regras práticas sob a forma 'nas mais das vezes'. Elas revelam regularidades; essas regularidades estão fundadas nas características que descrevem, embora em toda a situação tenhamos que pesar todas as características, umas contra as outras, para determinar qual será a relevante. Os deveres prima facie de Ross parecem assim capturar um elemento essencial da ética aristotélica.

O problema é que Aristóteles também apresenta uma alegação diferente concernente à estrutura básica do nosso domínio prático. Não é uma alegação acessória, mas contundente -, na verdade uma alegação central à sua posição filosófica. A alegação é que decisões morais devem ser formuladas em um padrão bem diferente, que eu chamaria aqui o 'padrão particularista'. Ele pode ser apresentado assim: 'A é bom / mau nas circunstâncias C para atingir um fim E’. Como Aristóteles inclui entre as circunstâncias o fim perseguido pelo agente ( $N E$ III 1 1111a5), pode-se escrever desse modo: 'A é bom / mau nas circunstâncias C'. Ora, um termo geral para as circunstâncias em Aristóteles é ta pros ton kairon (cf. NE II 2 1104a8-9; ver também III 1 1110a13-14), que significa 'nessa situação', 'aqui e agora', de modo que podemos reconstruir nossa fórmula assim: 'A é bom / mau hic et nunc'. No começo do tratado nicomaquéio sobre a virtude moral, Aristóteles escreve:

"Ora, que devemos agir <ROT: dein prattein> de acordo com a reta razão é um princípio comum e deve ser assumido - será discutido mais tarde, ou seja, tanto o que é, e como está relacionada às outras excelências. Mas isto deve ser acordado de antemão, que a explicação integral das questões de conduta deve ser dada em linhas gerais e não precisamente, como afirmamos no início que as concepções que demandamos devem estar em conformidade com o tema; temas concernidos com a conduta e questões do que é bom para nós não possuem fixidez, não mais do que questões de saúde. Sendo a concepção geral dessa natureza, a concepção dos casos particulares é ainda mais carente de exatidão; pois eles não se subsomem a qualquer arte ou conjunto de preceitos, mas os próprios agentes devem, em cada caso, considerar o que é apropriado à ocasião, como ocorre também na arte da medicina ou da navegação." (ENII 2 1103b31-1104a10) 
Esta passagem tem vários pontos que merecem ser examinados. Eu enfocaria em primeiro lugar a leitura usualmente aceita dessas primeiras linhas: 'deve ser assumido que agir de acordo com a reta razão é um princípio comum'. Esse é um dos raros usos de hupokeisthô na Ética Nicomaquéia (em contraste com a Ética Eudemia, onde é pervasivo). Mas uma variante, dada por um manuscrito Veneziano $\left(\mathrm{N}^{\mathrm{b}}\right)$, o qual lê por sua vez huperkeisthô, a lectio difficilior (registrado somente por Bekker). Essa última leitura significa: devemos adiar, pospor. A ideia, então, é que seria melhor evitar no momento a ideia comumente aceita de agir bem como agir segundo a reta razão. Na realidade, esse ponto será discutido mais tarde, no livro VI, e o resultado lá é que devemos substituir a frase secundum rationem pela frase cum ratione, considerada, ainda no livro VI, como mais apropriada. Assim, talvez, não é assumido prontamente que devemos agir de acordo à reta razão (como é suposto pela tradução revisada de Oxford). Em lugar disso, é dito, mais cautelosamente, que seria melhor pospor a discussão desse item por um tempo, não usando a comumente aceita expressão 'agir de acordo à reta razão'. Em contraste, há alguma coisa muito importante para ser imediatamente pressuposta: um discurso prático deve ser dado em linhas gerais e não precisamente. Outra vez há variantes nos manuscritos. A leitura dos editores (Bekker, Susemihl, Bywater) é: ho peri tôn praktôn logos, o que pode significar ou um conselho que um homem (moral) dá em uma situação, ou a concepção que o filósofo propõe sobre a natureza do conselho moral. Mas três importantes manuscritos $\left(\mathrm{K}^{\mathrm{b}} \mathrm{L}^{\mathrm{b}} \mathrm{M}^{\mathrm{b}}\right)$ dão outra leitura: ho peri tôn prakteôn logos. O significado agora é antes a proposição que se faz sobre o que devemos fazer, isto é, o conselho ou ordem proferido pelo prudente ou algo mais concernente a assuntos práticos. Não é o filósofo quem está falando, mas o homem prático. Qual é a leitura preferida? Encontramos ambos misturados de novo, o filósofo e o homem prático, no que pode ser considerada a cláusula principal dessa passagem: dei d' autous aei tous prattontas ta pros ton kairon skopein. O filósofo afirma: o agente deveria sempre levar em consideração a situação na qual se encontra. Essa é uma reivindicação universal. Mas em assuntos práticos é o oposto: decisões morais adotam um padrão particularista do tipo 'isso é o que deve ser escolhido hic et nunc'. Isso é o que o homem prático diz. O que o agente afirma se refere à situação na qual ele mesmo se encontra, de modo que, a menos que outras razões se apliquem, é limitada a essas circunstâncias hic et nunc. Pode ser o caso que o que o filósofo declare deva ser também apresentado em linhas 
gerais e não precisamente, mas parece ser mais natural tomar isso enquanto caracterizando o que o agente ou alguém mais envolvido na ação afirma sobre a própria ação. Assim, a falta de precisão diz respeito primariamente aos discursos feitos pelo homem prático, e, secundariamente, ao que o filósofo afirma sobre assuntos práticos.

Há outro ponto que merece ser examinado aqui. $\mathrm{Na}$ passagem citada acima, Aristóteles tem em mente dois tipos de sentenças ou logoi: uma concepção geral e uma particular. De acordo com os nossos resultados, uma está habilitada a afirmar que há dois tipos de sentenças práticas que os homens produzem, uma geral e outra particular. Aristóteles afirma que falta precisão às proposições gerais, e que, portanto, devem ser expressas em linhas gerais, e que até mesmo as proposições particulares são mais carentes de exatidão, já que essas últimas não se subordinam a qualquer arte ou conjunto de preceitos, pois os próprios agentes devem, em cada caso, considerar o que é apropriado à ocasião, como também ocorre na arte da medicina ou da navegação. ${ }^{17}$ As últimas, desse modo, não se subordinam a nenhuma arte ou conjunto de preceitos. A palavra, parangelia, é um hapax em Aristóteles; significa a intimação de alguém para ir a um tribunal, ou, como é o caso aqui, um conjunto de regras ou preceitos. Outra vez, o ponto é endereçado primeiramente não ao filósofo enquanto escreve sua filosofia moral, mas ao homem prático, quando ele argumenta sobre o que deve fazer. Essa passagem em $E N$ II 2 refere-se explicitamente à uma precedente, no livro I, capítulo 3. Nós lemos isso na ENI 3:

\begin{abstract}
"Ora, as ações nobres e justas, as quais são investigadas pela ciência política, exibem muita variedade e flutuação, de modo que podem ser pensadas como existindo somente por convenção, e não por natureza. $\mathrm{E}$ os bens também exibem uma flutuação similar, porque trazem prejuízo para muitas pessoas; anteriormente, homens foram arruinados em razão de sua riqueza, e outros em razão de sua coragem. Devemos nos contentar, por conseguinte, em falar de tais assuntos e com tais premissas para indicar a verdade aproximadamente e
\end{abstract}

\footnotetext{
17 É curioso observar que as artes da medicina e da navegação, no Político de Platão, sustentam a posição exatamente contrária: elas são dadas por Platão como exemplo do que é governado pelo conhecimento e não responde de modo algum a deliberações, mas somente à competência precisa ou ao conhecimento.
} 
em linhas gerais, e em falar sobre coisas as quais são somente nas mais das vezes verdadeiras e com premissas do mesmo gênero para alcançar conclusões do mesmo tipo.” (EN I 3 1094b14-22

Novamente, encontramos dois tipos de logoi nessa passagem. Em um deles, a verdade é somente indicada; no secundo, há premissas e silogismos, e consequentemente conclusões derivadas dos silogismos, mas ambas, premissas e conclusões, devem ser afirmadas em generalizações "nas mais das vezes". No primeiro caso, indicar a verdade encontra-se claramente em oposição a demonstrar a verdade, que é produto da ciência, a qual procede por demonstração estrita, e cujas premissas são necessárias. Indicar a verdade parece referir-se ao ato de exibir a verdade (prática) caso a caso, de apontá-la em cada situação (prática). Nós estamos assim lidando com opostos, uma coisa é demonstrar cientificamente um ponto, outra é indicar a verdade prática. Entre esses opostos encontram-se as proposições 'gerais'. Há, certamente, um $e$ que poderia não ser lido em sentido conectivo, mas explanatório: "nós podemos estar contentes em indicar a verdade aproximadamente e em linhas gerais, isto é, alcançar conclusões que são somente nas mais das vezes verdadeiras, pois nossas premissas são do mesmo tipo”. Mas parece mais natural tomá-lo como realmente aditivo e essa leitura encontra suporte na passagem da EN II, 2 que remete a ela. Por conseguinte, a ideia é que há duas camadas aqui: de um lado, há decisões particularistas, expressas em sentenças hic et nunc, de outro, generalizações do tipo 'a maior parte dos F são G', das quais podemos tirar conclusões do mesmo gênero.

Nós podemos, então, encontrar lado a lado duas classes de preceitos morais: regras do tipo 'nas mais das vezes', bem como decisões particularistas. Ora, Aristóteles afirma enfaticamente que todos os agentes devem, em cada caso, considerar o que é apropriado para a ocasião. Essa é uma alegação particularista forte. Aristóteles não está dizendo que sempre temos de levar em consideração as circunstâncias a fim de aplicar corretamente uma regra (a qual teria sido dada independentemente daquelas circunstâncias), mas mais propriamente que as decisões tomadas pelo agente estão profundamente inscritas nessas circunstâncias, de modo que elas são válidas somente para aquelas exatas circunstâncias, a menos que outras razões nos permitam ver para além das situações que supostamente são determinadas caso a caso. Esse ponto é realçado em muitas outras passagens na ética aristotélica. Quando Aristóteles examina a coragem, por exemplo, ele salienta o fato de que a 
bravura consiste em afrontar e sentir medo das coisas corretas e pelos motivos corretos, de modo correto e no momento correto (NE III 7 1115b17-18), especificando, por assim dizer, cada circunstância e destacando sua presença na constituição da decisão correta. Aristóteles é afeiçoado por uma metáfora para ilustrar esse ponto, a metáfora de atingir o alvo. O homem bom, o prudente, é stochastikos do bem, justamente como a virtude é stochastikê do bem. A palavra significa hábil em atingir, capaz de acertar, bem como proceder por conjecturas. Tudo isso transmite a ideia de atingir o alvo, mas de tal modo que há uma indeterminação radical nessa ação, a qual é sobrepujada momentaneamente em determinada ação, na medida em que a verdade prática é assim indicada, pois não há maneira de arranjar isso em um sistema que operaria como um código moral ou um plano para a agência humana.

$\mathrm{Na}$ verdade, o particularismo moral, bem como suas proposições hic et nunc, derivam diretamente da celebrada, embora disputada, doutrina da mediedade. Muitas das questões levantadas contra essa doutrina dependem da acusação de que ela é basicamente quantitativa. Mas, como foi mostrado recentemente, se uma leitura primariamente qualitativa é adotada, muitas dessas objeções perdem uma quantidade considerável de sua cogência. ${ }^{18} \mathrm{Em}$ qualquer caso, o ponto principal dessa doutrina é que decisões devem ser tomadas caso a caso, de modo que nosso melhor critério para ver a verdade em assuntos práticos é seguir o juízo dos que possuem sabedoria prática, pois eles podem ver onde ela se encontra, enquanto que as pessoas comuns são seguidamente enganadas pelas aparências. Essa é uma reiterada tese aristotélica: a virtude reside em um meio, isto é, é encontrada em algum lugar entre dois extremos, mas onde a virtude está exatamente somente pode ser determinada pela percepção moral, pois temos de levar em consideração todas as circunstâncias que circundam a ação. Essas decisões permanecem cerca das circunstâncias, são concebidas para responder a elas, e não vão além delas, a menos que outras razões se apliquem. A doutrina da mediedade deve assim fornecer uma base teorética para a reivindicação particularista em assuntos práticos, atribuindo a ela um lugar proeminente na ética aristotélica.

\footnotetext{
18 Uma das criticas mais severas contra a doutrina da mediedade foi feita por Kant, em sua Introdução à Metaphysik der Sitten; Kant propõe uma leitura estritamente quantitativa e assim reage contra ela. Rosalind Hursthouse, em reação a um artigo de Urmson, que favoreceu a leitura quantitativa, posicionou-se contra essa doutrina em Hursthouse (1980); veja também (1999). Mas veja também Christof Rapp (2006), quem convincentemente mostra como as perspectivas quantitativa e qualitativa mesclam-se uma à outra em tal doutrina.
} 
Existem regras gerais, do tipo 'a maior parte dos F são G', bem como as alegações particularistas, e parece que Aristóteles concede ao particularismo o papel mais importante em assuntos práticos.

\section{- III -}

À primeira vista, generalizações 'nas mais das vezes' e decisões particulares parecem compatíveis umas com as outras. Nas generalizações, como vimos, existe espaço para exceções; algumas dessas exceções podem ser localizadas sob sub-regras, mas, por fim, algumas delas resistem a qualquer estratégia de generalização e permanecem estritamente particulares. Mas, por que haveria algum problema em propor essas duas fórmulas para sentenças práticas? Assim, 'a maioria dos F são G' é compatível com 'poucos F não são G'. De fato, existem duas interpretações da reivindicação particularista, e em uma dessas duas interpretações, chamada aqui como a interpretação forte, existe incompatibilidade com as generalizações 'nas mais das vezes'. Nós já encontramos a interpretação forte ao citar $E N$ II 2. Os próprios agentes devem, em cada caso, agir como guiados pelas circunstâncias, buscando pelo que é o apropriado para aquela ocasião. Aristóteles também diz que as ações estão na classe dos particulares ( $E N$ III 1 1110b6), ou que a 'prática é concernente com os particulares' (ENVI 7 1141b16), ou, novamente, que é impossível que todas as coisas sejam estipuladas precisamente, uma vez que as ações dizem respeito aos particulares (Pol. II 8 1269a11-12). No mesmo estilo, agir bem consiste em agir de acordo com as circunstâncias de um jeito que o resultado seja fundamentalmente restringido por e dependente dessas circunstâncias. Agora 'a maioria dos tigres têm caudas' é compatível com nenhum tigre tem cauda no tempo presente (talvez porque todas elas foram cortadas para fazer afrodisíacos, para tomar um exemplo de Dancy ${ }^{19}$ ), mas a generalização nas mais das vezes implica que um tigre sem cauda é um espécime deficiente de seu tipo (pois sua natureza é ter uma cauda, ou melhor: ele normalmente deveria ter uma cauda). Mas a reivindicação de normatividade é incompatível com o que o exame particularista requer, a saber, que ele depende das circunstâncias de se $G$ ou não-G será o caso. Para ver isso, é conveniente reformular a reivindicação particularista como uma

${ }^{19}$ DANCY, 2004, p. 138. 
declaração não mais esta que aquela, pois não existe nenhuma norma fora das circunstâncias particulares na qual elas serão determinadas como $G$ ou não-G. Isto é precisamente o que é presumido pela interpretação forte: fora das circunstâncias, $F$ não é mais $G$ que não $G$. Tal indeterminação explica porque isto parece tão hostil para as generalizações nas mais das vezes. Assim, 'a maioria dos F são G' é compatível com algumas exceções, mas não é compatível com $F$ não sendo mais $G$ que não $G$. Pois, se esse fosse o caso, isso seria uma acidente cósmico que a maioria dos F são G.

Mas há, também, uma reivindicação mais fraca: para algumas situações (poucas), a decisão deve ser tomada de acordo com as circunstâncias, uma vez que nenhuma lei geral a recobre. Esta interpretação é compatível com as generalizações 'nas mais das vezes', pois só diz que poucos F não são $G$, o que está de acordo com dizer que a maioria dos F são G. Uma passagem na $E N \mathrm{~V}, 10$ vai nessa direção. Investigando sobre a natureza do equitativo, Aristóteles escreve:

"Por isso, o equânime é justo, e melhor que um tipo de justiça - não melhor que a justiça absoluta, mas melhor do que o erro que provém da incondicionalidade da afirmação. E isso é a natureza do equânime, uma correção da lei onde ela é deficiente devido à sua generalidade [dia to katholou]. De fato, isso é a razão por que todas as coisas não são determinadas pela lei, em função de que sobre algumas coisas é impossível estabelecer uma lei, de modo que um decreto é necessitado, pois quando a coisa é indefinida, a regra também é indefinida, como a régua de chumbo usada para ajustar as molduras de Lesbos; a régua adequa-se à forma da pedra e não é rígida, da mesma maneira que o decreto é adaptado aos fatos." (ENV 10 1137b24-32)

A lei é deficiente devido ao seu traço katholou - que significa, sendo um logos e um logos sendo intrinsicamente universal, que as leis não podem ser senão declarações gerais, sendo esta a razão do porquê algumas poucas ações caírem fora do seu domínio. Mas essas ações são poucas (1137b28). E sendo poucas elas não são uma ameaça às generalizações que admitem exceções, antes ao contrário: tais generalizações naturalmente aceitam algumas exceções. Assim, Aristóteles está realmente propondo dois esquemas: ou (a) umas poucas exceções, compatíveis com as generalizações 'nas mais das 
vezes'; ou (b) decisões particulares, aparentemente contrárias a qualquer codificação, uma vez que elas extraem seu poder das circunstâncias em que elas ocorrem. Algumas vezes Aristóteles ressalta (a) e sua compatibilidade com as leis, mas na maior parte do tempo ele ressalta (b) e sua incompatibilidade com as leis. De fato, o particularismo é disseminado na ética aristotélica, pois sempre que ele pretende dar um esboço geral do agir bem ou do que é agir virtuosamente, Aristóteles destaca o aspecto particularista, que é incompatível com generalizações. Ainda assim, é verdade que em algumas outras passagens ele nos proporciona uma interpretação mais fraca, que é compatível com generalizações.

Aristóteles parece então culpado por ser vacilante, mas ainda há mais para ser adicionado a esse cenário de hesitação conceitual. Nós também encontramos universalizações estritas na ética aristotélica, em que nenhuma exceção pode ser moralmente admitida. Aristóteles nós dá alguns exemplos na Ethica Nicomachea, Livro II: assassinato, roubo, adultério, entre as ações; malevolência, impudicícia e inveja, entre as emoções ou sentimentos. Não há nenhuma circunstância com a qual alguém teria cometido o assassinato correto, ou assassinado a pessoa certa, ou no momento certo, pois cometer um assassinato é totalmente inaceitável de um ponto de vista moral, sejam lá as circunstâncias sob as quais um ato foi realizado. Aqui está a passagem decisiva:

\footnotetext{
"Nem toda ação admite mediedade, tampouco toda emoção, pois algumas são denominadas em imediata conjunção com a vileza, como a malevolência, a impudicícia, a inveja e, quanto às ações, $\mathrm{o}$ adultério, o roubo, $\mathrm{o}$ assassinato. Com efeito, todas estas e as demais são censuradas por serem elas próprias vis e não por serem vis seus excessos ou faltas. Não há jamais como acertar a seu respeito, mas sempre se erra; tampouco o bem ou o não bem a respeito destas coisas está no praticar adultério com a mulher com quem, quando ou como se deve, mas o simples cometer qualquer um deles é errar.” (EN II 6 1107a817; trad. Marco Zingano)
}

Aqui, novamente, elas são poucas. Todavia, sua universalidade, por um lado, contrasta com as generalizações 'nas mais das vezes' (o anterior não admite exceções, enquanto o último está naturalmente aberto às exceções), e, por outro lado, com as decisões particularistas (em que o contraste vai ao seu zênite). Então parece como se existisse três modelos para a linguagem moral: 
(a) generalizações aberta às exceções, do tipo 'nas mais das vezes'; (b) universalizações estritas, que não admitem exceções; e (c) decisões particulares, feitas sob medida para cada situação em que o agente se encontra. Alguns pontos são imediatamente evidentes. Primeiro, (a) é compatível com uma interpretação fraca de (c), mas não com sua interpretação forte. Entretanto, é a última que está disseminada na ética aristotélica. Segundo, (a) e (b) requerem uma explicação sobre sua possível compatibilidade em moralidade. A possibilidade de compatibilidade parece forte, pois também são tratadas como compatíveis nas ciências naturais (não há dificuldade aparente em colocar lado a lado as universalizações estritas do tipo 'todo homem é racional' com as generalizações do tipo 'a maioria dos homens torna-se grisalha'). Terceiro, (b) e (c) competem diretamente uma contra a outra: ou a moralidade tem leis universais, em que não há exceção, ou é o caso em que os agentes devem sempre decidir caso a caso, de acordo com as circunstâncias, não tendo previamente leis universais para servir de diretrizes para a ação, isto é, o agente é deixado sozinho, sem leis universais.

\section{- IV -}

Se isso é correto, e se tem que contar com uma estrutura tripartite, a questão agora é: a linguagem moral em Aristóteles apresenta uma imagem coerente, ou deveríamos antes falar de um tipo de colcha de retalhos, cujos principais elementos são aquelas três camadas já mencionadas?

Há indícios que apontam para uma imagem incoerente. A fim de expor a definição de virtude moral, Aristóteles inicia seu argumento dizendo que dos três itens encontrados na alma - paixões, faculdades e disposições -, a virtude moral deve ser o terceiro, disposições. Para mostrar isso, ele descarta os dois primeiros candidatos, de modo que, dado por certo que a lista é exaustiva no que diz respeito aos itens da alma, segue-se que a virtude é uma disposição. Para descartar o primeiro candidato, a paixão, Aristóteles declara que nem a virtude nem o vício são paixões porque nós não somos chamados de bons ou maus em razão de tê-las; ao invés disso, somos elogiados ou censurados não por tê-las ou não tê-las, mas por tê-las de uma certa maneira (moderadamente, excessivamente e assim por diante). O mesmo ponto será feito concernentemente à faculdades: nós não somos elogiados ou censurados por sermos capazes de ter esta ou aquela afeição ou paixão, mas porque nós 
nos controlamos de uma certa maneira devido a esta ou aquela afeição. Aristóteles então propõe uma lista de paixões: apetite, raiva, medo, confiança, alegria, sentimento amigável - e inveja. A lista é elaborada em $E N$ II 5 11105b21-23. Algumas linhas adiante, em II 6 1107a8-12, como já vimos, é dito que existem algumas ações e paixões que implicam por seus próprios nomes que elas são más em si mesmas, e não apenas seu excesso ou deficiência, de modo que tê-las é sinal de censura moral (e não apenas tê-las de uma certa maneira, muito ou pouco). Entre as paixões mencionadas, como já vimos, está a inveja (1107a11). Mas algumas linhas anteriores, a inveja foi apresentada como uma paixão na forma que tê-la não é ainda um sinal de comportamento bom ou mau, pois o que vai determinar se a pessoa é moralmente boa ou má é tê-la de uma certa maneira e não apenas possuir a paixão em si. Isso é claramente uma inconsistência. E pode-se esperar encontrar mais incoerências espreitando em sua ética, particularmente porque nós vemos que a linguagem moral aristotélica pode ser concebida como um tipo de colcha de retalhos.

A doutrina da mediedade dá apoio ao particularismo moral em Aristóteles, como já vimos. A coisa correta a fazer recai em algum lugar entre os extremos, e determiná-lo depende de uma sensibilidade radical sobre as circunstâncias que envolvem a ação, de forma que o juízo prático varia com e é constituído por elas. Mas agora nós vemos que alguns juízos práticos são universais, do tipo 'assassinar é errado'. E a razão que Aristóteles dá para isso é que eles são analiticamente verdadeiros (pois, como ele diz, seus nomes já implicam maldade). Eles são então similares a tautologias, como 'onívoros comem carne': se alguém está familiarizado com esse sentido do termo 'onívoro', sabe que onívoros comem carne (pois eles por definição comem qualquer coisa que pode ser comida, e carne é algo que pode ser comida). Então, se alguém está familiarizado com o sentido do termo 'assassinar', ele claramente entende porque é sempre errado cometê-lo. Mas como reconciliar essas tautologias práticas com a principal ideia por trás da doutrina da mediedade, a saber, que um juízo prático é crucialmente dependente das circunstâncias e não pode ser determinado anteriormente às circunstâncias que circundam a ação? Aristóteles coloca maior peso em sua doutrina da mediedade, mas desde os tempos modernos, nos tornamos cada vez mais receosos que tal doutrina seja vazia, pois ela apenas diz que não se deve agir muito ou pouco. Agora, como agir virtuosamente é agir de acordo como o meio termo, e agir viciosamente é tanto exagerar quanto subutilizar uma 
coisa, esta celebrada doutrina parece ser apenas uma tautologia - e como tal não pode deixar de ser vazia. Então, mais uma vez, se encontra um sinal de incoerência no cerne da ética aristotélica: a doutrina da mediedade é presumida para nos dizer algo de substancial sobre o agir virtuosamente, mas de fato ela apenas expressa uma tautologia. Como essa doutrina tem outras consequências disputáveis, ela não está anunciando a sentença de morte para o meio termo dourado - e assim também para a reivindicação particularista aristotélica, como ela estaria baseada na doutrina da mediedade? Esta é a postura provocativa que Jonathan Barnes tomou:

"In the Ethics we can, I think, see Aristotle struggling with the logic and the sense of the Doctrine of the Mean: he becomes explicitly aware of its practical futility; and his discussions perhaps indicate an increasing disenchantment with its conceptual utility. Had Aristotle written a third ethical treatise, this celebrated Doctrine would not, I conjecture, have appeared in it." 20

\section{$-\mathbf{V}-$}

Se tudo isto é correto, dois problemas devem ser tratados imediatamente: primeiro, como harmonizar generalizações e particularismo em uma interpretação forte; segundo, como colocar juntos universalizações estritas e, novamente, particularismo em um sistema coerente. Na parte restante desse artigo, eu apenas examinarei o segundo problema, que, num certo sentido, é o mais urgente, pois não apenas nos dá a impressão de incoerência, mas nos transmite um forte sinal de contradição. Isto será finalmente ligado ao problema do particularismo, como eu o apresentei no início desse artigo.

O primeiro ponto, ao buscar harmonizar ambas as perspectivas, é notar que não apenas as universalizações estritas são mencionadas apenas depois da mediedade ter sido estabelecida, mas, mais importante, elas são explicadas em termos de sua doutrina. Aqui está a passagem que segue a que

20 BARNES, 1976, p. 26. 
foi citada acima, no final da seção III. Ela apresenta a razão do porque algumas ações e emoções têm nomes que já implicam mal moral:

"O mesmo vale para estimar que também a propósito do agir injustamente, ser covarde e ser intemperante há mediedade, excesso e falta; haveria assim, pois, mediedade do excesso e da falta, excesso do excesso e falta da falta. No entanto, assim como não há excesso e falta de temperança e coragem pelo fato do meio termo ser de certo modo um ápice, assim tampouco há, daqueles, mediedade, excesso ou falta, mas erra quem os pratique, pois, em geral, nem há mediedade do excesso e da falta nem excesso e falta da mediedade." (EN II 6 1107a18-27; trad. M. Zingano)

Como é evidente a partir dessa passagem, o ser imediatamente mau ou, dizendo de outra forma, o ser analiticamente mau, não é tomado como a última razão para elas serem estritamente esquecidas. De fato, sua analiticidade é explicada nos termos da doutrina da mediedade. Elas funcionam como se fossem extremos de ações ou emoções típicas, e como não há meio termo de excesso e deficiência, nem qualquer excesso de excesso, nem deficiência de deficiência, então também nessas ações não há meio termo nem qualquer excesso ou deficiência, mas, tão logo sejam feitas, elas estão erradas. A doutrina da mediedade é então chamada a fornecer uma explicação sobre seu estatuto analítico especial no interior do domínio moral. E, como vimos, Aristóteles parece muito afeiçoado a sua doutrina da mediedade, pois ele se esforça para apoiá-la por meio de sua terminologia metafísica, a despeito de sua tendência geral de manter separadas a ética e a metafísica.

Mas tal estratagema conceitual parece enganoso. Assassinato, por exemplo, não pode ser tão facilmente comparado à covardia ou temeridade, pois de uma forma significativa falta precisamente o que estaria no meio. Pode-se imaginar uma tríade do tipo: tolerar (deficiência) - matar - assassinar (excesso), mas obviamente matar não pode ocupar a posição média, pois o meio termo é uma ação virtuosa. Além do mais, há outro importante desacordo. O que conta como um ato de covardia ou temeridade somente pode ser determinado de acordo com a doutrina da mediedade, de acordo com as circunstâncias e, consequentemente, possui toda a falta de precisão que questões éticas possuem no que diz respeito aos seus termos médios positivos. Mas, obviamente, assassinato não é para ser determinado de acordo 
com as circunstâncias, como o próprio Aristóteles ressalta e, por isso, deve ser banido completamente, independentemente das circunstâncias.

A fim de encontrar uma maneira de sair dessas dificuldades, talvez se devesse concebê-la como um truque semântico. Importante lembrar que Aristóteles enfatiza os elementos semânticos como quando declara que algumas ações são então nomeadas de forma que elas já implicam maldade (1107a9-10). O truque seria: tome qualquer ação - ou emoção - o termo que se quiser, e construa-o em direção a uma nota moral negativa, de forma que o resultado seria que entender este termo implica entender porque a ação que é designada não deve ser feita. Uma nota moral negativa é uma nota qualitativa que pode ter diferentes expressões quantitativas. Tome por exemplo o prazer sexual. Agir licenciosamente em questões sexuais é qualitativamente o excesso cujas condições quantitativas podem variar, mas isso sempre será errado, pois isso é um dos extremos do comportamento sexual, e é visto como tal independentemente daquelas condições e circunstâncias envolvidas em suas variações quantitativas. Agora chame tal ação, mesmo que ela ocorra em relação a uma mulher casada, adultério; disso seguirá que sempre será errado cometer adultério. Se pode, então, criar uma proibição estrita, tal que qualquer adultério seja errado, independentemente das circunstâncias. Chegase, então, a uma regra do tipo: fazer $\mathrm{X}$ é absolutamente errado quando fazer $\mathrm{X}$ é de tal forma que a ação a que ela se refere é um extremo e o nome dessa ação tem embutido em si mesmo o tratamento moralmente indecoroso de seu comportamento. Tal truque pode ser aplicado a qualquer ato - ou emoção como assassinar $=$ perseguir deliberativamente vantagem pessoal por meio de matar alguém. Aristóteles fala disso, embora somente com algumas poucas palavras, mais isso é provavelmente devido ao fato de que sociedades escolhem apenas umas poucas ações e emoções cuja maldade inerente merece uma exposição especial, provavelmente a fim de ressaltá-las negativamente.

Vale a pena examinar como o adultério foi tratado pelos comentadores antigos. Alguns deles sentiram-se desconfortáveis sobre o adultério ser estritamente proibido, pois pode ser o caso em que cometer adultério é louvável, como, por exemplo, quando ele é cometido com a esposa de um tirano a fim de obter informação secreta dela, de forma a poder libertar toda a cidade da tirania. Aspásio sabia desse argumento. Eis o que ele escreve contra essas pessoas: 
"Não devemos ser confundidos por aqueles que afirmam que alguns adúlteros são louváveis, por exemplo, se alguém seduz a esposa de um tirano e, ficando perto dele deste modo, mata o tirano e liberta o país, pois isso não é adultério, mas antes o que o adultério implica aqui, pela palavra, devassidão, sendo superado pelos prazeres, e iniquidade. Da mesma forma, também, matar alguém de qualquer modo não é chamado assassinato: alguém pode matar uma pessoa justamente e meritoriamente, por exemplo, um inimigo saqueador. Mas a palavra 'assassinato' é compreendida como matar injustamente e contra a lei." (50, 2-9; tradução para o português a partir da tradução inglesa de Konstan)

Aspásio plausivelmente se refere a um mecanismo semântico a fim de manter a letra do texto aristotélico, segundo o qual o adultério não recai sob nenhuma das circunstâncias em que ele poderia ser moralmente aprovado. $\mathrm{O}$ mesmo truque é aplicado ao assassinato: há o ato de matar justamente, como matar um saqueador inimigo, mas assassinar é um ato de matar caracterizado negativamente, a saber, matar alguém injustamente e ilegalmente. No caso do adultério, isto implica luxúria, de forma que ter relações sexuais com a esposa de um tirano a fim de salvar o país não conta como um caso de adultério. Mais adiante, comentando sobre as linhas 1146b26-1115a3, que faz uma espécie de resumo do que foi examinado de I, 13 até III 5, Aspásio retorna ao tema do adultério:

\footnotetext{
"Uma pessoa temperante agira de acordo com a temperança, mas, quando a razão escolhe, pode seduzir a esposa de um tirano pela segurança da cidade. Mas ele fará isso incidentalmente, e fará coisas temperantes por elas mesmas." (80.16-18, tradução para o português a partir da tradução inglesa de Konstan)
}

Propriamente falando, ele não está cometendo adultério, mas salvando a cidade da tirania, e é apenas acidentalmente ou per accidens que ele está envolvido em adultério. Esta é outra maneira de dizer que cometer adultério é buscar prazer lascivo com uma mulher casada, de forma que fazer sexo com uma mulher casada não é em si mesmo cometer adultério, pois se pode fazer isso sem luxúria. Assim, o truque semântico tem uma linhagem antiga e não 
é insignificante, pois vem diretamente de Aspásio, um importante comentador peripatético.

Mas este mecanismo semântico é realmente satisfatório? Pode-se ter algumas dúvidas a esse respeito. Isto parece funcionar bem com o adultério, o que é compreensível, pois vemos algo de errado com a proibição do adultério por completo, uma vez que há algumas circunstâncias em que pode ser moralmente aceitável fazer sexo com uma mulher casada. Mas, ao invés disso, pensemos no caso de estupro. Ele seria apenas outro caso de excesso na ânsia por desejo sexual, exceto que tem em seu próprio nome implicado sua maldade, como um mecanismo pedagógico que as sociedades usam para alertar seus cidadãos contra alguns delitos? Isto não parece uma questão simples. Aristóteles escreve que nem toda ação nem toda paixão ou emoção admite um meio termo (1107a8-9). Em seguida, ele acrescenta, como vimos: pois algumas têm nomes que já implicam maldade. Agora, podemos tomar a declaração para como a que nos proporciona uma razão para isso ser assim (o que podemos chamar de sua ratio essendi) ou uma forma de reconhecer que isso é assim (o que podemos chamar de sua ratio cognoscendi). A interpretação do truque semântico toma isso como nos proporcionando a razão do porque tais palavras têm esse estatuto peculiar. Nessa interpretação, ou a natureza analítica desses termos conflitam com o cerne da doutrina da mediedade, ou, como parece mais provável, a natureza analítica é explicada em termos de sua doutrina, além de um mecanismo para incorporar, em alguns termos, um traço de maldade, com a finalidade de promover a moralidade mais facilmente. Mas se as tomamos como fornecendo para nós uma forma de mostrar que palavras são essas - que eu rotulei como sua ratio cognoscendi -, então ainda se tem que apresentar a razão para tal comportamento peculiar no que diz respeito a essas palavras.

Agora, parece-me que Aristóteles está adotando a interpretação ratio cognoscendi. E uma forma de mostrar isso é revelar a razão do porque tais ações têm um estatuto peculiar. Para fazer isso, se deve prestar especial atenção aos exemplos que ele dá: malevolência, impudicícia, inveja, entre emoções; adultério, roubo, assassinato, entre ações. Mesmo que ainda não se compreenda qual é a razão delas terem essa característica especial, pode-se sentir segurança em adicionar outros exemplos a esses, tais quais: violência sexual como estupro ou agir geralmente com crueldade. Por que isso? Porque, em um sentido muito básico, ser moral consiste em considerar as outras pessoas como receptores de respeito e consideração, da mesma forma que eu sou. 
Em seu nível mais elementar, a moralidade nos faz tomar as outras pessoas como nós, e isto implica em não mais situar a mim mesmo em uma posição absoluta ou central. Esta característica básica é capturada pela noção filosófica de altruísmo: reconhecer as outras pessoas como tais, de forma que o egoísmo natural é temperado pelo reconhecimento dos outros como pessoas como eu. Naturalmente, existem diferentes formas de chegar a reconhecer as outras pessoas como tais, como os diferentes sistemas morais históricos testemunham, e os filósofos têm proposto vários critérios para explicar a estrutura básica do ponto de vista moral. Tal reconhecimento pode ser tão tênue quanto possível, ou, antes, denso - pode-se falar de uma pessoa racional de forma geral, independentemente de tempo e cultura, ou de uma pessoa historicamente determinada, vivendo em tal país e adotando tais e tais hábitos. O que Aristóteles está fazendo aqui, eu suponho, é traçar os limites da moralidade, configurando as fronteiras do reconhecimento das outras pessoas como dignas e merecedoras de respeito. Esta é uma posição bastante básica. Ela ainda não diz se essa posição é a de um ponto de vista imparcial dos outros, ou uma perspectiva comprometida e engajada comum, mas ela já faz uma clara contraposição entre e o que está dentro e o que está fora do domínio moral. Dar lugar as outras pessoas a partir de meu próprio ponto de vista: esta parece ser a linha demarcatória do ponto de vista moral. Nesse sentido, ela traça a linha entre o comportamento moral e não moral. A linha divisória é feita a partir de atitudes básicas, como a recusa do assassinato e roubo; a desaprovação moral de impudicícia e malevolência; a desaprovação moral da violência sexual e crueldade, e assim por diante. Todas elas compartilham a característica básica de reconhecimento da alteridade além do egoísmo, em um espaço comum e, como tais, elas traçam em conjunto as fronteiras da moralidade.

É por isso que, desde a antiguidade, o adultério foi tomado como um item estranho nessa lista, pois ele certamente lhe pertence, e realmente pertence aos sistemas morais, mas não parece constituir suas fronteiras da mesma que a proibição da crueldade e estupro o fazem. Todavia, o adultério não está inteiramente fora do lugar nessa lista. $\mathrm{Na}$ verdade, cada item nessa lista que traça as fronteiras da moralidade transmite um valor e, como um valor, ele está profundamente enraizado em práticas sociais e culturais. Talvez o adultério imponha-se como um valor básico na medida em que a mulher é tomada como pertencendo ao homem e, então, alguém estaria protegendo sua propriedade em banindo o adultério completamente, uma vez que os 
gregos o consideravam como uma ofensa mais grave que o estupro, e mesmo a mais grave ofensa em comportamento sexual. Mas em uma sociedade que exalta a igualdade sexual, ou em que os direitos individuais começam a emergir como socialmente relevantes, o adultério recua para o segundo lugar, e a proibição do estupro aparece preferencialmente como uma atitude moral básica. Para nós, a liberdade de religião pode plausivelmente contar como um valor demarcatório no sentido requerido aqui, mas isso é, então, devido a nossa própria história, profundamente afetada por experiências, expectativas e disputas religiosas. Em um sentido relevante, o adultério nos recorda da natureza social e cultural dos valores que traçam as fronteiras da moralidade, os limites em que a alteridade é reconhecida, fora da qual ela é meramente subserviente ao autointeresse. Mas esses valores não são apenas lembranças, eles são mandamentos fortes: não assassinar, não estuprar e assim por diante. Concebidos com maior ou menor peso, eles ainda possuem alguma espessura, sendo o conteúdo do que é requerido para constituir as fronteiras da moralidade em uma dada sociedade.

Suponho que Aristóteles estava insinuando tal ponto ao afirmar que algumas ações e emoções não admitem mediedade, mas que devem ser banidas completamente. É importante notar que essas ações e emoções produzem proibições estritas ou interdições absolutas. Agora, de um ponto de vista lógico, não há diferença relevante entre um universal negativo e outro positivo; no entanto, parece haver uma importante diferença de um ponto de vista moral. Em um artigo bem conhecido sobre dilemas morais, E. J. Lemmon escreve:

\footnotetext{
"A man may know that he ought to tell the truth, and do so, because he holds as a moral principle that one should always tell the truth - a slightly unrealistic example, since moral principles tend to be prohibitive rather than compelling: a better example would be that of a man who knows he is not to commit adultery with a certain woman, and does not do so, because he holds it to be a moral ruling that one should at no time commit adultery". ${ }^{21}$
}

21 LEMMON, 1962, p. 139-140. 
E. J. Lemmon não está falando aqui do que eu chamei de fronteiras da moralidade, mas está apontando para uma diferença moral importante entre regras afirmativas universais e estritas proibições negativas. Aristóteles não endossa a anterior ${ }^{22}$, mas aceita a última. E ele aceita a última porque, como proibições universais, ou mandamentos negativos, elas traçam os limites da moralidade: ou você está dentro, e então você deve procurar pela resposta moral correta para sua situação, ou você está fora e, então, a alteridade é subserviente ao seu egoísmo. É por isso que são negativas, e absolutas: não há comunicação entre os dois lados do ponto de vista moral.

\section{$-\mathbf{V I}-$}

Para concluir, deixem-me voltar a um aspecto do particularismo moral, como Dancy o concebe. De acordo com ele, se pode imaginar uma moralidade capturada em um conjunto de princípios holísticos contributivos, constituindo uma ética dos princípios. Isso é possível, ele admite, mas seria uma espécie de acidente cósmico, para o qual nenhuma explicação é possível. O particularista, em contraste, manterá que o que é relevante em um caso não é necessariamente relevante em outro caso. Ele não negará que os princípios morais são possíveis; ele apenas dirá que um sistema moral não depende de um suprimento de tal conjunto que é aceito como tal. Este é o caso, por exemplo, de infligir dor gratuita às vitimas. Dancy alega que o motivo disso reter um valor negativo em todas as circunstâncias não deriva do fato de isso ser uma razão, mas do conteúdo dessa razão. Isto é, deriva de seu conteúdo peculiar, a saber, aquele que vai contra a natureza humana (como a dor vai), que lhe confere uma posição especial dentro de uma moralidade particularista. Eu não estou certo que a distinção entre ser

\footnotetext{
22 A passagem principal está em EN VI 1 1138b25-34, sobre a então chamada 'regra' de ouro, a saber, que se deve escolher o que é intermediário, não o excesso nem o defeito: "mas tal proposição, embora verdadeira, não é de modo algum esclarecedora; pois em todas as outras atividades as quais são objeto de conhecimento é de fato verdadeiro afirmar que nós não devemos trabalhar em maior ou menor quantidade, mas sim em quantidade média e como dita a reta razão; mas se um homem tivesse esse conhecimento, ele não poderia conhecer mais nada - por exemplo, não deveria saber que tipo de remédios administrar ao nosso corpo se alguém dissesse 'todos que são prescritos pela arte médica, e tal como prescreve quem possui tal arte'. Deste modo, é necessário no que concerne aos estados da alma também não somente que essa proposição verdadeira deveria ser feita, mas que também deveria ser determinado o que a reta razão é, e qual é o padrão que fixa isso."
} 
uma razão e ser o conteúdo de uma razão possa ser aplicada à ética de uma forma esclarecedora, ao menos não para explicar por que o particularismo pode lidar com princípios morais. Soa mais como um tipo de compromisso: o particularismo moral deve governar nossas práticas morais, mas alguns princípios gerais e mesmo universais podem ser encontrado aqui e ali, como traços de átomos em um diferente cosmos holístico. Em certo sentido, a razão padrão (default reason) de Dancy é exatamente este tipo de compromisso, isto é, ela apenas abre espaço para alguns princípios em ética, mas a moralidade basicamente equivale a uma decisão caso a caso. E como tal, a moralidade não requer tal suprimento de princípios servindo de fundamento.

Penso que se nós retornarmos a Aristóteles, estaremos em uma melhor posição para ver por que e como qualquer sistema moral depende de um suprimento de regras universais. $\mathrm{Na}$ verdade, essas regras têm uma natureza peculiar. Elas são todas proposições universais negativas. Como mandamentos universais negativos, elas funcionam como proibições estritas. Como proibições estritas, elas traçam as fronteiras da moralidade. O que se deve fazer quando se está dentro desses limites não é determinado pelos mesmos - para Aristóteles, é tarefa do homem prudente determinar o que é a coisa correta a fazer, pois o homem com sabedoria prática leva em conta as circunstâncias em torno da ação, em uma forma tipicamente particularista. Mas o particularismo não pode funcionar sem que essas fronteiras tenham sido previamente traçadas em linhas (mais ou menos) espessas, não permitindo nenhuma exceção - e é por isso que ele depende crucialmente do suprimento de tais mandamentos negativos.

Tradução: Denis Coitinho Silveira e João Hobuss

\section{Referências bibliográficas}

ASPASIUS. On Aristotle's Nicomachean ethics 1-4, 7-8 (Tranl. D. Konstan). Cornell: Cornell University Press, 2006.

BARNES, J. Introduction to The Ethics of Aristotle (transl. by J.A.K. Thomson, revised by H. Tredennick). New York: Penguin Books, 1976.

BARNES, J. The Complete Works of Aristotle - the Revised Oxford Translation. 2 vols. Princeton: Princeton University Press, 1984.

DANCY, J. Moral Reasons. Oxford: Blackwell, 1993. 
. Ethics without Principles. Oxford: OUP, 2004

- Moral Particularism. Stanford Encyclopedia of Philosophy (http://plato. stanford.edu), 2001, rev. 2009.

DREIER, J. Contemporary Debates in Moral Theory. Oxford: Blackwell, 2006.

HARDIE, W. F. R. Aristotle's Ethical Theory. Oxford: OUP, 1980.

HOOKER, B.; LITTLE, M. (eds.), Moral Particularism. Oxford: OUP, 2000.

HURSTHOUSE, R. "A false doctrine of the mean". Proceedings of the Aristotelian Society 81, 1980, p. 57-72.

. On Virtue Ethics. Oxford: OUP, 1999.

IRWIN, T. "A Ética como uma Ciência Inexata”. Analytica I 3, 1996, p. 1373 .

. (2000), "Ethics as an Inexact Science: Aristotle's ambitions for moral theory": In: HOOKER, B.; LITTLE, M. (eds.), Moral Particularism. Oxford: OUP, 2000, p. 100-129.

LEMMON, E. J. "Moral Dilemmas". The Philosophical Review 71, 1962, p. 139-158.

MCDOWELL, J. Mind, Value, and Reality. Harvard: Harvard University Press, 1998, 2002.

NATALI, C. The Wisdom of Aristotle. NewYork: SUNY Press, 2001.

PRICE, A. W. "Was Aristotle a Particularist?". Proceedings of the Boston Area Colloquium in Ancient Philosophy vol. xxi, 2005, p. 191-212.

RAPP, C. "What use is Aristotle's Doctrine of the mean". In: REIS, B (ed.). The Virtuous Life in Greek Ethics. Cambridge, Cambridge University Press, 2006.

ROSS, D. The Right and the Good. Oxford: OUP, 1930, 2002.

. The Foundations of Ethics. Oxford, OUP, 1939.

SAINT-HILAIRE, B. Morale à Nicomaque. 3 vols. Paris: 1856.

ZINGANO, M. Ethica Nicomachea I 13 - III 8. Tratado da Virtude Moral. São Paulo: Odysseus, 2008. 